\section{Poor consumers' preferences for nutritionally enhanced foods}

Nutritionally enhanced foods

Rosina Wanyama and Theda Gödecke

Department of Agricultural Economics and Rural Development, University of Goettingen, Goettingen, Germany

Matthias Jager

International Center for Tropical Agriculture (CIAT), Cali, Colombia, and

Matin Qaim

Department of Agricultural Economics and Rural Development, University of Goettingen, Goettingen, Germany

\begin{abstract}
Purpose - Micronutrient malnutrition is a public health problem in many developing countries, especially in the poorest population segments. Fortification and other food-based approaches, such as using more nutritious ingredients in processing, could help to address this problem, but little is known about poor consumers' attitudes toward nutritionally enhanced foods. The purpose of this paper is to analyze whether poor consumers in Africa would purchase foods with more nutritious ingredients and the related willingness and ability to pay. Design/methodology/approach - A survey and choice experiment were conducted with 600 randomly selected households in the poorest neighborhoods of Nairobi (Kenya) and Kampala (Uganda). Participants were asked to choose between various alternatives of porridge flour with different types of nutritional attributes. The data were analyzed with mixed logit models. Porridge flour is widely consumed among the urban poor, so that the example can also provide interesting broader lessons.

Findings - Poor consumers welcome foods that are micronutrient-fortified or include new types of nutritious ingredients. However, willingness to pay for nutritional attributes is small. New ingredients that are perceived to have little effect on taste and appearance are seen more positively than ingredients that may change food products more notably.

Practical implications - New nutritionally enhanced foods have good potential in markets for the poor, if they build on local consumption habits and are not associated with significant price increases.

Originality/value - This is among the first studies to explicitly analyze poor consumers' preferences for nutritionally enhanced foods.
\end{abstract}

Keywords Consumer attitudes, Nutrition, Diets

Paper type Research paper

\section{Introduction}

Micronutrient malnutrition remains one of the major public health challenges in many developing countries. An estimated $2 \mathrm{bn}$ people still suffer from micronutrient deficiencies (Development Initiatives, 2017). Such deficiencies are largely due to inadequate intake of essential vitamins and minerals. The prevalence of micronutrient malnutrition is particularly high among poor households, whose diets are dominated by cheap staples and low consumption of more nutritious foods (Bouis and Saltzman, 2017; Gelli et al., 2015). Health effects of micronutrient deficiencies include increased mortality and morbidity, poor pregnancy outcomes, reduced work productivity, and impaired mental and physical development in children (Black et al., 2008). The resulting health burden is associated with large economic and human costs (Gödecke et al., 2018; Horton and Steckel, 2013).

(C) Rosina Wanyama, Theda Gödecke, Matthias Jager and Matin Qaim. Published by Emerald Publishing Limited. This article is published under the Creative Commons Attribution (CC BY 4.0) licence. Anyone may reproduce, distribute, translate and create derivative works of this article (for both commercial \& non-commercial purposes), subject to full attribution to the original publication and authors. The full terms of this licence may be seen at: http://creativecommons.org/licences/by/4.0/legalcode 
$\mathrm{BFJ}$

121,3

Various interventions exist to address micronutrient malnutrition. These include food supplementation, industrial fortification, biofortification and dietary education programs, among others (Bouis and Saltzman, 2017; Thompson and Amoroso, 2011). Food-based approaches that do not require recurring public support are generally seen as more sustainable. Biofortification i.e. the breeding of staple food crops for higher micronutrient contents - can be a promising intervention especially in rural areas, where households do not consume a lot of processed foods (Bouis et al., 2011; Qaim et al., 2007). Industrial fortification and related approaches to increase the nutritious value of processed foods can be promising avenues in urban areas (Thompson and Amoroso, 2011; Gibson, 2010). In any case, successfully introducing nutritionally enhanced foods requires good understanding of consumer preferences. Poor people's preferences in particular need to be understood, not only because they are the main target group for nutritional improvements but also because their preferences may differ from those of richer households. Oftentimes, the poor have lower nutritional awareness and lower willingness and ability to pay.

Several studies were conducted in developing countries to evaluate consumer attitudes toward new types of nutritious foods (De Groote et al., 2017; Jackson et al., 2013; De Steur et al., 2010; Mabaya et al., 2010). A few studies focused on consumer acceptance of biofortified crops, mostly in rural areas (De Groote et al., 2014; Meenakshi et al., 2012). Others worked with samples from urban areas and nutritional enhancements of processed foods. Jackson et al. (2013) had carried out sensory evaluation of different porridges in Botswana and found that participants liked the taste of nutritionally enhanced recipes but were hardly willing to pay more than for traditional and less nutritious porridge flour. De Groote et al. (2017) analyzed consumer attitudes toward fortified foods in urban Senegal and also found a low willingness to pay (WTP) a premium, which increased somewhat with more nutrition information provided.

While these studies deliver important insights, they do not necessarily reflect attitudes of the urban poor. Existing studies with urban consumers did either not differentiate by income groups (De Groote et al., 2017; Jackson et al., 2013) or they used samples in which poor households were underrepresented (Mabaya et al., 2010). This is considered a drawback because the problem of urban poverty may increase with the growth of informal settlements (Tacoli, 2017; UN-Habitat, 2010). Here, we address this research gap by analyzing poor consumers' preferences for nutritionally enhanced foods using choiceexperimental data collected in the poorest neighborhoods of Nairobi (Kenya) and Kampala (Uganda). We focus on slum areas, where poverty and malnutrition rates are particularly high (World Bank, 2017). The choice experiment was designed using hypothetical porridge flour with different types of nutritional attributes.

Porridge is one of the most popular food items consumed by children and adults in poor households in Africa. Especially in urban areas, households typically buy porridge flour. However, most of the porridge flour available in the market is based on low-nutrient cereals (Ndagire et al., 2015). Nutritional enhancement could be achieved by using micronutrientfortified flours or by using composite flours that also include ingredients with higher nutritional content. Composite flours with non-cereal ingredients could add to the diversity of food groups consumed. This is particularly relevant for poor households, whose diets are typically characterized by low levels of diversity. In comparison to preparing different food groups separately, the use of composite flours could also help to save cooking time and energy (De Groote et al., 2017). We include micronutrient-fortification, new types of ingredients and other attributes into our choice experiment to analyze consumer preferences and WTP.

Porridge is chosen as an example of a widely consumed food product in urban Africa, but the results are more general and can also provide lessons for other types of processed foods. The findings may be of interest to public and private sector actors in the food system wishing to develop and introduce nutritionally enhanced products and improve the functioning of related value chains. 


\section{Materials and methods}

\subsection{Sample selection and household survey}

This study builds on survey and experimental data collected from households in the poorest neighborhoods of Nairobi and Kampala, the capital cities of Kenya and Uganda. Data collection took place between November 2016 and February 2017. The use of data from two cities and two countries in East Africa allows interesting comparisons and some conclusions that may hold for poor urban households in the region in general. In Kenya and Uganda, it is estimated that more than 50 percent of the urban population actually lives in slums, even if formal census data may suggest otherwise (World Bank, 2017).

A multi-stage sampling procedure was used to select households to participate in our study. First all the constituencies in Nairobi County and divisions in Kampala District were listed and ordered based on average income, poverty levels and other indicators of living standards using official country data (KNBS, 2015; Ministry of Lands, Housing and Urban Development, 2014; UBOS, 2014). Two constituencies/divisions with the highest poverty levels or lowest standard of living in each city were purposively selected: Mathare and Kibra (formerly Kibera) constituencies in Nairobi, and Kawempe and Nakawa divisions in Kampala.

Second, we sampled the poorest wards and villages ("village" is an administrative unit also in metropolitan zones and should not be confused to stand for rural areas here) in the selected constituencies and divisions based on information from local administrative offices. In Nairobi, we selected three wards in Kibra (Laini Saba, Lindi, and Makina) and one village in Mathare (Mradi). In Kampala, we selected two villages in Kawempe (Bwaise I and Bwaise III) and two villages in Nakawa (Kinawataka and Banda).

Finally, in these wards and villages, households were selected randomly, using the random walk method. A random walk method was most appropriate for selecting the households given that census data for these slum areas do not exist and that most of the houses have temporary structures and no permanent address. Sampling was based on households with at least one child aged 6-59 months. In total, 600 households were interviewed, 300 in Nairobi and 300 in Kampala.

Data were collected through personal interviews conducted in local languages by well-trained enumerators. We used structured questionnaires with tablet computers. The questionnaire was carefully pretested in the field prior to the actual survey. It included sections on the general characteristics of households, income-earning activities, food and non-food consumption, and other relevant aspects. Each selected household also participated in the choice experiment to elicit preferences for nutritionally enhanced porridge flour. To ensure high data quality, the choice experiment was conducted with the person in the household responsible for food purchases and food preparation.

\subsection{Choice experiment}

We use a choice experiment to analyze consumer preferences for a set of porridge flour attributes. Choice experiments have been widely used in consumer and environmental studies (Veettil et al., 2011; Louviere et al., 2010), and more recently also in research on agricultural value chains (Meemken et al., 2017; Ochieng et al., 2017; Vassalos et al., 2016). Choice experiments are grounded on Lancaster's consumer behavior and McFadden's random utility theory (Adamowicz et al., 1998; McFadden, 1973). The underlying assumption is that consumers derive utility from the attributes of a good rather than the good itself. Since choice experiments usually look at a set of attributes of a particular good, each with different attribute levels, it is assumed that the choices of consumers reflect the combinations of attribute levels that yield the highest subjective utility.

Following Louviere et al. (2000), the different formats of choice modeling include contingent choice, contingent ranking, and contingent rating. We use contingent choice, where consumers are asked to choose one type of porridge flour out of a set of options, because this mimics a typical market situation best (Schipmann and Qaim, 2011; Louviere 
$\mathrm{BFJ}$ 121,3

\section{8}

Table I.

Summary of attributes and attribute levels used in the choice experiment and Woodworth, 1983). Consumer's choice of a particular porridge flour can be modeled using the random utility framework as follows:

$$
U_{i j}=V_{i j}+\varepsilon_{i j}=\alpha A_{j}+\beta X_{i}+\varepsilon_{i j},
$$

which implies that the utility $(U)$ of consumer $i$ associated with the selected porridge flour $j$ can be decomposed into a deterministic component $(V)$ and a stochastic element $(\varepsilon)$. The deterministic component is further decomposed into a vector of porridge flour attributes $(A)$ and socioeconomic characteristics $(X)$ ) of consumer $i$ that may influence his/her choice. $\varepsilon$ is an independently and identically distributed error term that captures unobserved factors influencing consumer's choice. $\alpha$ and $\beta$ are parameters to be estimated. A rational consumer $i$ will choose option $j$ if the utility derived from $j$ is greater than the utility derived from alternative $k$, that is, $V_{i j}>V_{i k}$.

\subsection{Porridge flour attributes}

Prior to designing the choice experiment, a rapid market survey was carried out to identify the type of porridge flour consumers are currently using and the set of product attributes that might be of interest to food manufacturers, retailers and consumers. In Nairobi, the most common porridge flour is currently made from millet, whereas in Kampala, porridge flour is mostly made from maize. Based on the rapid market survey, we decided to include four porridge flour attributes in the experiment, as shown in Table I. The attributes are identical for the experiments in both cities, but some of the attribute levels differ as these were tailored to the local conditions.

The first attribute we used in the choice experiment was product price per kilogram of porridge flour. The base price was set to actually observed market prices for commonly consumed porridge. At the time of the survey and experiment, the average price of milletbased porridge flour in Kenya was 100 Kenyan shillings (KES) per kg (equivalent to US $\$ 0.98$ ). The average price of maize-based porridge flour in Uganda was 2,400 Ugandan shillings (UGX) per kg (equivalent to US\$0.67). We used six price levels, the base price, -10 and -20 percent of the base price, and $+10,+20$ and +30 percent above the base price. As not all participants were conversant with percent calculations, the price levels were presented in monetary terms, as shown in Table I.

The second attribute was porridge ingredients. Five attribute levels were used, with each level representing a specific combination of different ingredients (Table I). In total, we

\begin{tabular}{lcll}
\hline Attribute & Level & Nairobi & Kampala \\
\hline Price per kg: market price & 1 & $100 \mathrm{KES}$ & $2,400 \mathrm{UGX}$ \\
Market price $+(-20 \%)$ & 2 & $80 \mathrm{KES}$ & $1,920 \mathrm{UGX}$ \\
Market price $-(-10 \%)$ & 3 & $90 \mathrm{KES}$ & $2,160 \mathrm{UGX}$ \\
Market price $+(10 \%)$ & 4 & $110 \mathrm{KES}$ & $2,640 \mathrm{UGX}$ \\
Market price $+(20 \%)$ & 5 & $120 \mathrm{KES}$ & $2,880 \mathrm{UGX}$ \\
Market price $+(30 \%)$ & 6 & $130 \mathrm{KES}$ & 3,120 UGX \\
Ingredients & 1 & Millet only & Maize only \\
& 2 & Millet and maize & Maize and millet \\
& 3 & Millet and beans & Maize and beans \\
& 4 & Millet and OFSP & Maize and soybeans \\
Fortified with vitamin A, iron and zinc & 5 & Millet and amaranth leaves & Maize and amaranth grains \\
& 1 & No & No \\
Level of processing & 2 & Yes & Yes \\
& 1 & Straight-run flour & Straight-run flour \\
Notes: KES, Kenyan shillings; UGX, Ugandan & shillings; OFSP, orange fleshed sweet potato
\end{tabular}


considered seven ingredients with slight differences between the two cities to better account for local availability and familiarity. The seven ingredients included maize, millet, beans, soybeans, orange fleshed sweet potatoes (OFSPs), amaranth grains and amaranth leaves. These ingredients differ in their nutritional composition. Millet and maize, currently the main ingredients of porridge flour in Nairobi and Kampala, are common staples that mostly contain carbohydrates (Nuss and Tanumihardjo, 2010). Some varieties of millet are also good sources of calcium, iron, and phosphorous (Dayakar Rao et al., 2017). Beans are a good source of protein and vitamin B (Hayat et al., 2014); some varieties also contain relatively high levels of minerals such as iron and zinc (Broughton et al., 2003). Similarly, soybean is a good source of dietary protein. OFSP contains beta-carotene, a precursor of vitamin A, in addition to several other vitamins and minerals (Low et al., 2007). Likewise, amaranth leaves have good nutritional value in terms of beta-carotene, iron, calcium, vitamin $\mathrm{C}$ and folic acid (Priya et al., 2007), whereas amaranth grain contains important minerals such as calcium, magnesium, iron and zinc. We assume that producing and selling composite porridge flour with these ingredients would enhance micronutrient intakes of poor urban consumers.

The third attribute was also related to micronutrients and refers to fortification of the porridge flour with vitamin A, iron and zinc. This attribute is captured with a simple binary variable indicating whether or not the flour is micronutrient-fortified. Commonly consumed porridge flour is not micronutrient-fortified. The use of vitamin A, iron and zinc in the choice experiment is based on the fact that deficiencies in these three micronutrients are responsible for the largest health burden in most developing countries (Gödecke et al., 2018).

The fourth attribute was the level of processing, with two attribute levels, namely, sifted and straight-run flour. Sifted flour is highly refined flour processed mostly by large food manufacturers, while straight-run flour is unrefined whole meal processed by smaller hammer mills (Mukumbu and Jayne, 1995). The two processing levels differ somewhat in texture and taste. Due to the whole grain components included, straight-run flour is more satiable and of higher nutritional value.

\subsection{Experimental design}

By combining the four selected attributes and their respective attribute levels, we obtain a full factorial set of $120\left(6 \times 5 \times 2^{2}\right)$ possible combinations. In practice, it is not possible to present all these alternatives to the respondents. Following Louviere et al. (2000), we used an orthogonal procedure to select a fraction of the full factorial set, resulting in 54 alternatives for each city. These 54 alternatives were divided into 18 choice sets, with each choice set containing three alternatives. The first two alternatives were varying with respect to attribute levels, while the third alternative always represented the traditional porridge flour in the specific setting.

The 18 choice sets were randomly assigned to three blocks, each containing 6 choice sets. This was necessary to obtain efficient responses, as going through 18 choice sets would have been tiring for the respondents and could have led to low data quality. In our design, each participant was asked to respond to only six choice sets, whereby the choice sets were graphically supported with choice cards. One example of a choice card is shown in Figure 1. In each choice card, respondents were asked to choose their preferred product out of the three presented alternatives. This exercise was repeated six times in a row. Since we sampled 300 respondents in both cities (600 in total), each block was assessed by 100 consumers.

Poor consumers are usually not very aware and knowledgeable about nutritional details and dietary requirements. Hence, one important question for our research was how much nutritional information to present to respondents prior to or during the experiment. Previous research showed that providing a lot of nutritional details can enhance the WTP for nutritionally enhanced foods (De Groote et al., 2017; Mabaya et al., 2010). This is plausible, even though receiving comprehensive nutrition information prior to purchasing food is not necessarily what happens in real market situations. On the other hand, providing

Nutritionally enhanced foods 


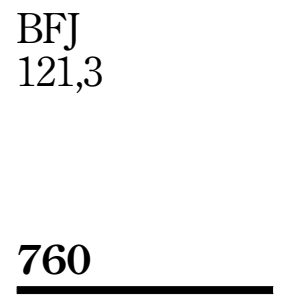

Figure 1.

Example of a choice card used in Nairobi, Kenya

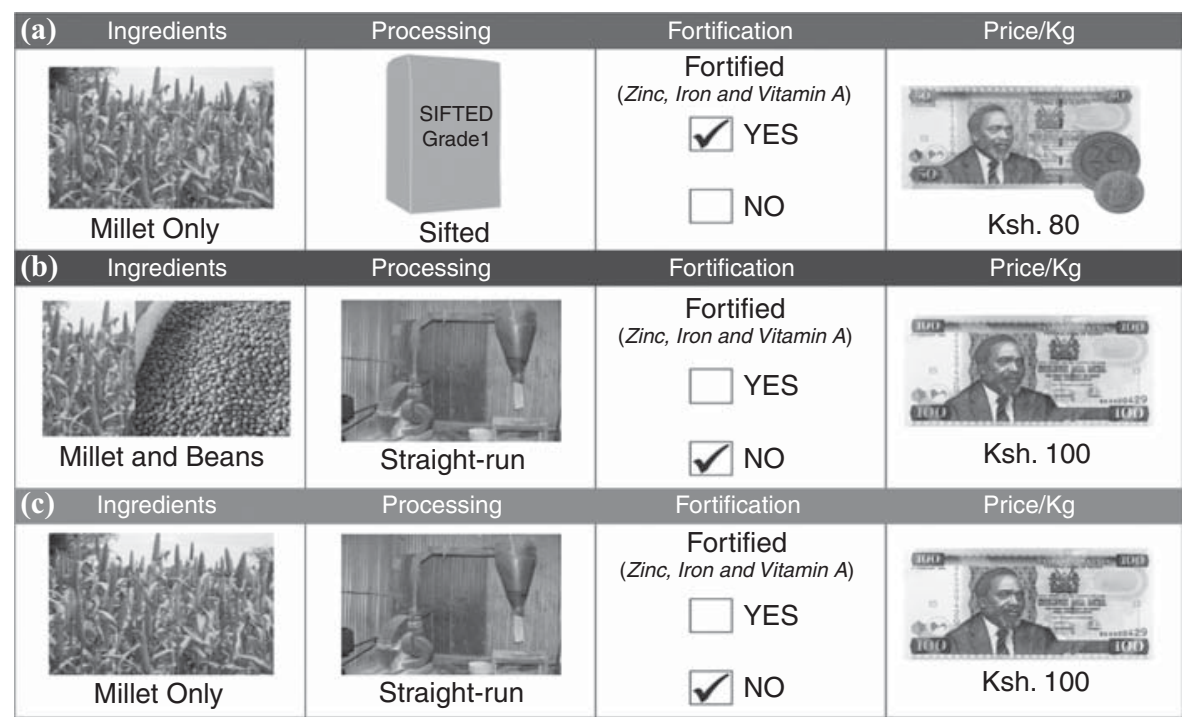

no nutrition information at all would not have served the purpose to better understand poor consumers' attitudes toward nutritionally enhanced foods. We therefore decided to use a middle way, where we refrained from presenting details of possible nutrition and health benefits, but briefly mentioned nutritional advantages of the flour attribute levels similar to what one might find on labels printed on packaged food. The explanations and instructions we used are shown in the Appendix.

\subsection{Estimation procedure}

We use the mixed logit model (random parameter logit) and a simulated maximum likelihood estimator to analyze the choice-experimental data (Train, 2009; Hole, 2007). The mixed logit model relaxes some of the rigid assumptions of alternative models, such as the standard multinomial logit model or conditional logit models. The mixed logit does not require the independence of irrelevant alternatives assumption, meaning that unobserved factors are allowed to be correlated. Mixed logit models also allow for preference heterogeneity across respondents, meaning that utility parameters may vary between individuals (Hensher et al., 2005). We assume a lognormal distribution, which permits us to restrict the coefficient of price to negative values (Hole and Kolstad, 2012). Regardless of the preferences for other attributes, it is safe to assume that consumers prefer lower-priced porridge, holding other things constant.

When the flour attributes are uncorrelated, the estimation model can be expressed as:

$$
Y_{i j m}=\alpha A S C+\beta P_{i j m}+\gamma A_{i j m}+\varepsilon_{i j m},
$$

where $Y$ is a binary decision variable that takes a value of 1 if consumer $i$ chooses alternative $j$ in choice scenario $m$, and 0 otherwise. $P$ is the price attribute, while $A$ is a vector of the other flour attributes, including ingredients, level of processing, and micronutrientfortification. $A S C$ is the alternative specific constant, which captures consumer's general preferences for nutritionally enhanced porridge flour. The $A S C$ is a dummy variable taking a value of 1 if the base scenario with the traditional porridge flour is chosen, and 0 otherwise. A positive coefficient $\alpha$ implies a positive preference for the traditional porridge flour, while a negative coefficient implies a preference for nutritionally enhanced flour, holding the 
concrete attribute levels constant. The coefficients $\gamma$ indicate the direction of preference for each of the flour attributes. A positive coefficient $\gamma$ means that consumers prefer the particular attribute, and a negative coefficient indicates a negative attitude.

The base model in Equation (2) allows for preference heterogeneity, but it is not able to identify how specific socioeconomic factors may influence consumer preferences for nutritionally enhanced flour. To better understand the potential role of socioeconomic factors, we specify a different version of the mixed logit model, where we include interaction terms between the $A S C$ and consumer characteristics, as follows:

$$
Y_{i j m}=\alpha A S C+\beta P_{i j m}+\gamma A_{i j m}+\delta\left(A S C \times X_{i}\right)+\varepsilon_{i j m},
$$

where $X$ is a vector of socioeconomic factors that might influence consumer preferences, such as sex, age, education and income.

The estimated parameters from the base model in Equation (2) can also be used to compute the WTP for the different attributes. WTP is obtained by dividing the attribute's coefficient by the price coefficient and multiplying by -1 (Hole and Kolstad, 2012):

$$
W T P_{j}=\frac{\partial P}{\partial A_{j}}=-\frac{\gamma_{j}}{\beta} .
$$

\section{Results}

\subsection{Sample characteristics}

Table II shows summary statistics characterizing the socioeconomic situation of sample households. The data reflect that the survey were carried out in the poorest neighborhoods of Nairobi and Kampala. The average per capita income in the total sample is $\$ 1.52$ per day expressed in purchasing power parity). Most of the households depend on casual employment for income generation, or on own small informal businesses. Almost three-quarters of the households live below the international poverty line of $\$ 1.90$ per capita and day. Poverty rates are significantly higher in the Kampala subsample (90 percent) than in the Nairobi subsample (56 percent). Relative differences in living standards are also reflected in larger asset values owned by households in Nairobi.

Nutritional awareness and knowledge are low among sample households. In the survey, we asked whether respondents had received any nutrition-relevant information from any source during the 12 months prior to the interview. Fewer than 40 percent responded "yes" to

\begin{tabular}{|c|c|c|c|c|c|c|}
\hline \multirow[b]{2}{*}{ Variables } & \multicolumn{2}{|c|}{ Full sample $(n=600)$} & \multicolumn{2}{|c|}{ Nairobi $(n=300)$} & \multicolumn{2}{|c|}{ Kampala $(n=300)$} \\
\hline & Mean & $\mathrm{SD}$ & Mean & $\mathrm{SD}$ & Mean & $\mathrm{SD}$ \\
\hline Male-headed household (dummy) & 0.67 & 0.47 & 0.85 & 0.36 & 0.49 & 0.50 \\
\hline Age of household head (years) & 35.72 & 10.71 & 35.84 & 8.63 & 35.60 & 12.46 \\
\hline Education of household head (years) & 8.68 & 3.58 & 9.63 & 2.64 & 7.70 & 4.12 \\
\hline Household size & 4.96 & 2.13 & 5.09 & 1.91 & 4.84 & 2.33 \\
\hline Nutrition information received (dummy) & 0.39 & 0.49 & 0.41 & 0.49 & 0.37 & 0.48 \\
\hline Salaried employment (dummy) & 0.21 & 0.41 & 0.29 & 0.45 & 0.13 & 0.34 \\
\hline Casual employment(dummy) & 0.63 & 0.48 & 0.68 & 0.47 & 0.58 & 0.50 \\
\hline Self-employed (dummy) & 0.40 & 0.49 & 0.36 & 0.48 & 0.44 & 0.50 \\
\hline Income per day per capita (PPP\$) & 1.52 & 1.21 & 2.00 & 1.24 & 0.96 & 0.89 \\
\hline Proportion of poor (dummy) ${ }^{\mathrm{a}}$ & 0.73 & 0.44 & 0.56 & 0.50 & 0.90 & 0.30 \\
\hline Household assets (PPP\$) & 505.75 & 787.77 & 612.12 & 941.68 & 399.39 & 577.74 \\
\hline
\end{tabular}
this question, with no significant differences between households in Nairobi and Kampala.

Notes: PPP, purchasing power parity. ${ }^{a}$ Households are classified as poor when per capita income is below the international poverty line of $\mathrm{PPP} \$ 1.90$
Nutritionally enhanced foods 
$\mathrm{BFJ}$

121,3

762

For those that had received nutrition information, the majority (71 percent) mentioned public health centers or clinics as the information source. It should be stressed that a small child ( $<60$ months) living in the household was one of the eligibility criteria for study participation. Households with small children tend to visit health centers more often than households without children for vaccinations, medical checks, and treatments of diseases. During these visits, nutrition information is also sometimes provided, even though this is usually confined to specific recommendations. Other sources of nutrition information that were mentioned by fewer respondents include television, radio, newspapers, charity organizations, as well as relatives and friends.

\subsection{Preferences for nutritionally enhanced porridge flour}

Regression results of the mixed logit models are shown in Table III for Nairobi and in Table IV for Kampala. We start with discussing the results for Nairobi. The significant parameter estimates in the base model in Table III suggest that all flour attributes, except for processing level (sifted flour), are relevant for consumer preferences in Nairobi. The standard deviation estimates in the lower part of Table III indicate significant preference heterogeneity. The estimate for the alternative specific constant (ASC) is negative and significant, meaning that consumers have a general preference for nutritionally enhanced porridge flour. This is a welcome finding, as it shows that consumers are open to try out new versions of flour with improved nutritional values. In other words, they may potentially dislike specific attributes, but they have a positive attitude toward nutritional enhancement in general.

\begin{tabular}{|c|c|c|c|c|}
\hline \multirow[b]{2}{*}{ Variables } & \multicolumn{2}{|c|}{ Base model } & \multicolumn{2}{|c|}{ With interaction terms } \\
\hline & Coefficient & $\mathrm{SE}$ & Coefficient & $\mathrm{SE}$ \\
\hline \multicolumn{5}{|l|}{ Parameters } \\
\hline ASC $(1=$ traditional porridge flour $)$ & $-0.87 * * *$ & 0.24 & -0.04 & 0.90 \\
\hline Price $(\%)$ & $-7.04^{* * * *}$ & 1.58 & $-8.94^{* * * *}$ & 2.66 \\
\hline Millet and maize & $0.49 * * *$ & 0.12 & $0.53^{* * * *}$ & 0.13 \\
\hline Millet and beans & $0.37 * * *$ & 0.12 & $0.40^{* * * *}$ & 0.12 \\
\hline Millet and OFSP & $-0.32^{* * *}$ & 0.14 & $-0.33^{* *}$ & 0.14 \\
\hline Millet and amaranth leaves & $-0.50 * * * *$ & 0.14 & $-0.59 * * *$ & 0.15 \\
\hline Sifted flour & 0.08 & 0.10 & 0.11 & 0.09 \\
\hline Fortified with vitamin $\mathrm{A}$, iron and zinc & $1.14^{* * * *}$ & 0.17 & $1.14 * * *$ & 0.15 \\
\hline ASC $\times$ male & & & -0.01 & 0.02 \\
\hline ASC $\times$ age & & & -0.07 & 0.39 \\
\hline ASC $\times$ education & & & -0.02 & 0.05 \\
\hline ASC $\times$ income & & & -0.004 & 0.90 \\
\hline \multicolumn{5}{|l|}{ Standard deviations } \\
\hline ASC & $0.84^{* *}$ & 0.36 & $0.83^{* * * *}$ & 0.27 \\
\hline Price & $2.25 * * *$ & 0.69 & 3.15 **** & 1.17 \\
\hline Millet and maize & $1.20 * * *$ & 0.19 & 1.17 *** & 0.18 \\
\hline Millet and beans & $0.78^{* * * *}$ & 0.26 & $0.77^{* * * *}$ & 0.24 \\
\hline Millet and OFSP & $1.30 * * *$ & 0.26 & $1.34 * * * *$ & 0.26 \\
\hline Millet and amaranth leaves & $1.22 * * *$ & 0.24 & $1.21 * * *$ & 0.28 \\
\hline Sifted flour & $0.53 * *$ & 0.21 & $0.53 * * *$ & 0.19 \\
\hline Fortified with vitamin $\mathrm{A}$, iron and zinc & $1.54 * * *$ & 0.22 & $1.56^{* * * *}$ & 0.19 \\
\hline$n$ (number of households) & 300 & & 300 & \\
\hline$n$ (number of observations) & 5,400 & & 5,184 & \\
\hline Log likelihood & $-1,545.75$ & & $-1,485.87$ & \\
\hline$\chi^{2}$ & $397.75^{* * *}$ & & $364.65^{* * * *}$ & \\
\hline
\end{tabular}

Table III.
Mixed logit estimates for consumers in Nairobi
Notes: ASC, alternative specific constant. The reference categories for the flour attributes are millet flour, straight-run flour and not fortified. ******Significant at the 5 and 1 percent levels, respectively 


\begin{tabular}{|c|c|c|c|c|c|}
\hline \multirow[b]{2}{*}{ Variables } & \multicolumn{2}{|c|}{ Base model } & \multicolumn{2}{|c|}{ With interaction terms } & \multirow{2}{*}{$\begin{array}{r}\text { Nutritionally } \\
\text { enhanced }\end{array}$} \\
\hline & Coefficient & $\mathrm{SE}$ & Coefficient & $\mathrm{SE}$ & \\
\hline \multicolumn{6}{|l|}{ Parameters } \\
\hline ASC $(1=$ traditional porridge flour $)$ & $-1.01^{* * * *}$ & 0.30 & -0.46 & 0.79 & \\
\hline Price $(\%)$ & $-6.55^{* * * *}$ & 0.95 & $-8.48 * * *$ & 2.60 & \\
\hline Maize and millet & $0.81^{* * * *}$ & 0.18 & $0.85^{* * * *}$ & 0.20 & \\
\hline Maize and beans & $-0.54 * * *$ & 0.16 & $-0.62^{* * * *}$ & 0.21 & 763 \\
\hline Maize and soybeans & $0.51^{* * * *}$ & 0.14 & $0.47 * * * *$ & 0.17 & \\
\hline Maize and amaranth grains & $-0.27^{*}$ & 0.15 & -0.11 & 0.18 & \\
\hline Sifted flour & 0.08 & 0.12 & 0.09 & 0.14 & \\
\hline Fortified & $1.72 * * *$ & 0.17 & $1.90 * * *$ & 0.22 & \\
\hline ASC $\times$ male & & & $0.69^{*}$ & 0.39 & \\
\hline ASC $\times$ age & & & 0.01 & 0.01 & \\
\hline ASC $\times$ education & & & $-0.13^{* * * *}$ & 0.05 & \\
\hline ASC $\times$ income & & & 0.19 & 0.22 & \\
\hline \multicolumn{6}{|l|}{ Standard deviations } \\
\hline ASC & $1.44^{* * * *}$ & 0.40 & 0.44 & 0.42 & \\
\hline Price & $2.34 * * *$ & 0.45 & $3.15^{* *}$ & 1.22 & \\
\hline Maize and millet & $1.18 * * * *$ & 0.22 & $1.30 * * *$ & 0.24 & \\
\hline Maize and beans & $1.16^{* * * *}$ & 0.25 & $1.53 * * *$ & 0.34 & \\
\hline Maize and soybeans & $0.99 * * *$ & 0.18 & $1.17 * * *$ & 0.24 & \\
\hline Maize and amaranth grains & $1.29 * * * *$ & 0.22 & $1.44^{* * * *}$ & 0.26 & \\
\hline Sifted flour & $0.98^{* * *}$ & 0.17 & $1.07 * * *$ & 0.20 & \\
\hline Fortified & $1.44 * * *$ & 0.19 & $1.61^{* * * *}$ & 0.26 & \\
\hline$n$ (number of households) & 300 & & 300 & & \\
\hline$n$ (number of observations) & 5,400 & & 4,320 & & \\
\hline Log likelihood & $-1,313.00$ & & $-1,045.83$ & & \\
\hline$x^{2}$ & $385.07 * * * *$ & & $265.58^{* * * *}$ & & $\begin{array}{l}\text { 1able IV. } \\
\text { Mixed logit estimates }\end{array}$ \\
\hline \multicolumn{6}{|c|}{$\begin{array}{l}\text { Notes: ASC, alternative specific constant. The reference categories for the flour attributes are maize flour, } \\
\text { straight-run flour and not fortified. *******Significant at the } 10,5 \text { and } 1 \text { percent levels, respectively }\end{array}$} \\
\hline
\end{tabular}

Looking at the coefficient estimates for the flour attributes in Table III more closely, we see a negative price coefficient, meaning that, ceteris paribus, consumers prefer lower prices. This is unsurprising and was actually imposed through the choice of the lognormal distribution. More interesting is the large absolute value of the price coefficient, which indicates a high price-responsiveness among these groups of poor consumers. Low-income consumers are often observed to react more price-responsively than better-off households.

In terms of porridge flour ingredients, the estimation results suggest that consumers have a positive preference for composite flour containing maize or beans in addition to millet, but a negative preference for composite flour containing OFSP or amaranth leaves. This is interesting and points at differences in how particular ingredients are perceived. Maize is the major staple food in Kenya traditionally eaten as ugali, a thick mush. This is not so different from porridge, so that consumers probably expect little changes in taste and appearance when maize is included as a porridge ingredient. Beans are consumed in multiple forms in Kenya, and are therefore also easily comprehensible as a new ingredient in porridge flour. This is quite different for OFSP and amaranth leaves. OFSP are popular, especially among children, but are usually eaten in Kenya as boiled tubers, not as flour. Hence, consumers likely expect more notable changes in taste, texture, and appearance when they think of OFSP as a new ingredient in porridge flour. This is also true for amaranth leaves, which are mainly consumed as vegetables, but not as flour.

The positive and significant coefficient for the attribute "fortification" reveals a strong preference for flour where vitamin $\mathrm{A}$, iron and zinc has been added by the manufacturer 
BFJ

121,3

during processing. The size of the coefficient suggests that this is a highly preferred attribute among poor consumers, as it adds nutritious value without changing most of the other preferred characteristics. While traditional porridge flour is not fortified in Kenya, consumers are familiar with the idea of fortification, from other processed foods that they have consumed themselves or have at least seen before in food market shelves.

Table IV shows the regression estimates for Kampala. In spite of the different subsamples used, the main results are quite similar to those observed for Nairobi. The ASC coefficient in the base model shows that - also in Kampala - consumers have a general preference for nutritionally enhanced porridge flour. Moreover, the negative price coefficient and its large absolute value indicate a relatively large price-responsiveness.

In terms of ingredients, consumers in Kampala have a positive preference for composite flour that contains millet or soybean in addition to maize, but a negative preference for composite flour that contains beans or amaranth grains as new ingredients. The negative preference for beans is interesting and in contrast to the results for Nairobi. However, in Uganda, beans are mostly served as a sauce along with popular staple foods, so that consumers have bigger problems imagining beans as a porridge flour ingredient. The negative preference for amaranth grain can probably be explained by the fact that many consumers are not very familiar with this type of food. While amaranth grain can be purchased in certain markets and shops, it is not as widely available as other grains, so that many consumers do not have a clear idea of its taste and other characteristics.

As in Nairobi, and also in Kampala, we observe a strong consumer preference for porridge flour that is fortified with vitamin A, iron and zinc.

\subsection{Role of socioeconomic characteristics}

To explain possible causes of preference heterogeneity, we also estimated models with interaction terms between the ASC and socioeconomic variables, as explained in Equation (3). These additional estimation results are also shown in Table III for Nairobi and in Table IV for Kampala. In Nairobi, none of the interaction terms is statistically significant, meaning that the general preferences for nutritionally enhanced porridge flour are not significantly influenced by sex, age, education or income (Table III). This is a welcome finding, as it implies that nutritionally enhanced porridge will also be acceptable by the very poor with only low levels of education. This does not mean that some promotion would not be required when introducing nutritionally enhanced products, but it suggests that the poor would be open to try these products also without a major nutrition education campaign.

In Kampala, some of the coefficients of the interaction terms between ASC and socioeconomic variables are statistically significant (Table IV). The positive coefficient for the male interaction term means that male household heads have a preference for traditional porridge flour that is not nutritionally enhanced. This result could be due to the fact that women are often more nutrition-conscious in their consumption and food choice behavior. The negative coefficient for the education interaction term implies that the positive preference for nutritionally enhanced porridge flour increases with additional years of schooling. While this result for Kampala is different than for Nairobi, it is not unexpected, because mean education levels are still lower in Kampala. Yet, also in Kampala, the general preference for nutritious foods is not influenced by income, which is encouraging for projects and policies that aim to target the poorest of the poor.

\subsection{Willingness to pay (WTP)}

The WTP estimates for each of the attributes are shown in Table V, separately for Nairobi and Kampala. Only attribute levels with statistically significant coefficients in the base model are shown. A first observation is that - in spite of their statistical significance - the WTP estimates are all quite small in terms of their absolute magnitude. This means that 
consumers are hardly willing and able to pay more for nutrition attributes, in spite of their general preference for nutritionally enhanced foods. In other words, consumers are open to purchase nutritionally enhanced porridge flour, but only if the new products do not come with a hefty price markup.

Looking into further details of Table V, consumers in Nairobi would be willing to pay around $0.4-0.5$ percent more for composite flour containing millet plus maize or beans. On the other hand, they would require a price discount 0.3-0.5 percent to accept composite flour containing OFSP or amaranth leaves. The highest WTP of +1.1 percent is observed for the attribute of micronutrient-fortification. Consumers in Kampala have a positive WTP for composite flour containing maize plus millet or soybeans, but a negative WTP for composite flour containing beans or amaranth grain. And again, the highest WTP of +1.7 percent is observed for micronutrient-fortification.

\section{Discussion and conclusion}

Micronutrient malnutrition remains a public health problem in many developing countries, especially in the poorest population segments. Micronutrient-fortification and other foodbased approaches, such as using more nutritious ingredients in food processing, could help to address the problem, but little is known about poor consumers' attitudes toward nutritionally enhanced foods. Would poor consumers purchase foods with more nutritious ingredients, even when their nutrition knowledge is limited? And are the poor willing and able to pay more for nutritionally enhanced products? These are important questions that we have addressed in this study, using choice-experimental data from the poorest neighborhoods of Nairobi and Kampala in East Africa. We have used the example of porridge flour, a widely purchased product among poor urban households, to analyze the acceptance of different types of nutritional attributes.

Results have shown that poor consumers generally welcome porridge flour that is micronutrient-fortified or includes new types of nutritious ingredients, in spite of their low nutritional knowledge and awareness. However, the willingness and ability to pay for the new nutritional attributes is small. In other words, poor consumers are open to purchase nutritionally enhanced foods, but only if the new products are introduced without a significant price markup. This is consistent with De Groote et al. (2017), who reported that urban consumers in Senegal had low WTP a premium for fortified foods. However, De Groote $e t$ al. (2017) did not focus on poor consumers in particular, so that our findings add to the existing literature.

In terms of concrete product attributes, our results suggest that new and more nutritious food ingredients that are perceived to have little or no effect on taste, texture and appearance of established products are judged more positively than ingredients that consumers feel

\begin{tabular}{llcrrr}
\hline Region & Attributes & Mean WTP (\%) & SD & Lower CI & Upper CI \\
\hline \multirow{2}{*}{ Nairobi } & Millet and maize & 0.49 & 0.05 & 0.39 & 0.58 \\
& Millet and beans & 0.36 & 0.02 & 0.32 & 0.41 \\
& Millet and OFSP & -0.32 & 0.05 & -0.42 & -0.22 \\
& Millet and amaranth leaves & -0.49 & 0.05 & -0.58 & -0.40 \\
& Fortified with vitamin A, iron and zinc & 1.11 & 0.07 & 0.98 & 1.24 \\
Kampala & Maize and millet & 0.81 & 0.04 & 0.72 & 0.89 \\
& Maize and beans & -0.54 & 0.04 & -0.62 & -0.45 \\
& Maize and soybeans & 0.51 & 0.04 & 0.42 & 0.59 \\
& Maize and amaranth grains & -0.25 & 0.05 & -0.34 & -0.17 \\
& Fortified with vitamin A, iron and zinc & 1.69 & 0.06 & 1.57 & 1.81
\end{tabular}

Notes: WTP, willingness to pay; OFSP, orange fleshed sweet potato; CI, confidence interval referring to the $95 \%$ confidence level
Nutritionally enhanced foods

\section{(a)}


$\mathrm{BFJ}$

121,3

could have more notable changes on product characteristics. Similar findings were reported in Botswana where participants in a sensory evaluation experiment of nutritionally enhanced foods gave lower ratings for recipes associated with notable changes in common and familiar attributes (Jackson et al., 2013). In a different study, Mabaya et al. (2010) found that color and appearance were ranked as very important attributes by consumers in Botswana. But again, unlike our work, these previous studies did not concentrate on poor consumers in particular.

Our results have several important implications for public and private sector actors in the food system. First, nutritionally enhanced foods have good potential in markets catering for the urban poor, if the nutritional enhancements are not associated with significant price rises. Larger price markups would probably mean that the poorest of the poor would stick to the less nutritious but cheaper alternatives. Second, nutrition education campaigns could certainly help to improve dietary quality more broadly, but costly campaigns may not be needed to successfully introduce nutritionally enhanced foods. Clear labeling combined with limited advertisement may suffice for consumers to buy these foods and appreciate specific nutritional advantages. Third, depending on local food consumption habits and preferences, consumers see certain recipes and product modifications positively, while evaluating others negatively. This means that the development of nutritionally enhanced foods needs to build on profound understanding of local food and dietary preferences. Fourth, processed foods with new types of ingredients may possibly create positive spillovers along the value chains. A rising demand for nutritious ingredients from urban manufacturers may provide incentives for farmers and food traders to increase production and market efficiency, which could probably trigger positive income and nutrition effects also in rural areas.

Our study also has several research implications. First, our analysis is based on four selected attributes that were found relevant for porridge flour in East Africa. Follow-up research could test other relevant foods and nutrition attributes in different geographical settings. Second, choice experiments with stated preference data, as we used, can be associated with a certain degree of hypothetical bias. Experiments where consumers reveal their actual preferences by purchasing concrete products may be useful to confirm the findings. Third, we did not analyze the cost of producing and processing nutritionally enhanced foods. Research on efficient sourcing and processing is important to keep consumer prices low. Finally, more research is needed to analyze the broader value chain implications of new types of nutritionally enhanced food products, including possible effects for agricultural and rural development.

\section{Acknowledgments}

This research was financially supported by the German Federal Ministry for Economic Cooperation and Development (BMZ) through the project "Making Value Chains Work for Food and Nutrition Security of Vulnerable Populations in East Africa" (Grant No. C-030-16), led by the International Center for Tropical Agriculture (CIAT). The authors thank the Kenya Agricultural and Livestock Research Organization (KALRO) and the National Agricultural Research Organization (NARO) in Uganda for their cooperation and support during the field work.

\section{References}

Adamowicz, W., Boxall, P., Williams, M. and Louviere, J. (1998), "Stated preference approaches for measuring passive use values: choice experiments and contingent valuation", American Journal of Agricultural Economics, Vol. 80 No. 1, pp. 64-75.

Black, R.E., Allen, L.H., Bhutta, Z.A., Caulfield, L.E., De Onis, M., Ezzati, M., Mathers, C. and Rivera, J. (2008), "Maternal and child undernutrition: global and regional exposures and health consequences", The Lancet, Vol. 371 No. 9608, pp. 243-260. 
Bouis, H.E. and Saltzman, A. (2017), "Improving nutrition through biofortification: a review of evidence from HarvestPlus, 2003 through 2016”, Global Food Security, Vol. 12, pp. 49-58.

Bouis, H.E., Hotz, C., McClafferty, B., Meenakshi, J.V. and Pfeiffer, W.H. (2011), "Biofortification: a new tool to reduce micronutrient malnutrition", Food and Nutrition Bulletin, Vol. 32 No. S1, pp. S31-S40.

Broughton, W.J., Hernandez, G., Blair, M., Beebe, S., Gepts, P. and Vanderleyden, J. (2003), "Beans (Phaseolus spp.) - model food legumes”, Plant and Soil, Vol. 252 No. 1, pp. 55-128.

Dayakar Rao, B., Bhaskarachary, K., Arlene Christina, G.D., Sudha Devi, G. and Vilas, A.T. (2017), Nutritional and Health Benefits of Millets, ICAR_Indian Institute of Millets Research (IIMR) Rajendranagar, Hyderabad, p. 112. available at: http://millets.res.in /m_recipes/Nutritional_ health_benefits_millets.pdf (accessed June 15, 2018).

De Groote, H., Gunaratna, N.S., Okuro, J.O., Wondimu, A., Chege, C.K. and Tomlins, K. (2014), "Consumer acceptance of quality protein maize (QPM) in East Africa", Journal of the Science of Food and Agriculture, Vol. 94 No. 15, pp. 3201-3212.

De Groote, H., Kariuki, S.W., Traore, D., Taylor, J.R., Ferruzzi, M.G. and Hamaker, B.R. (2017), "Measuring consumers' interest in instant fortified pearl millet products: a field experiment in Touba, Senegal”, Journal of the Science of Food and Agriculture, Vol. 98 No. 6, pp. 2320-2331.

De Steur, H., Gellynck, X., Storozhenko, S., Liqun, G., Lambert, W., Van Der Straeten, D. and Viaene, J. (2010), "Willingness-to-accept and purchase genetically modified rice with high folate content in Shanxi Province, China", Appetite, Vol. 54 No. 1, pp. 118-125.

Development Initiatives (2017), "Global nutrition report 2017: nourishing the SDGs", Development Initiatives, Bristol.

Gelli, A., Hawkes, C., Donovan, J., Harris, J., Allen, S.L., De Brauw, A., Henson, S., Johnson, N., Garret, J. and Ryckembusch, D. (2015), "Value chains and nutrition: a framework to support the identification, design, and evaluation of interventions", IFPRI Discussion Paper No. 01413, International Food Policy Research Institute, Washington, DC.

Gibson, R.S. (2010), "Strategies for preventing multi-micronutrient deficiencies: a review of experiences with food-based approaches in developing countries", in Thompson, B. and Amoroso, L. (Eds), Combating Micronutrient Deficiencies: Food-Based Approaches, CAB International and FAO, Rome, pp. 7-27.

Gödecke, T., Stein, A.J. and Qaim, M. (2018), "The global burden of chronic and hidden hunger: trends and determinants", Global Food Security, Vol. 17, pp. 21-29.

Hayat, I., Ahmad, A., Masud, T., Ahmed, A. and Bashir, S. (2014), "Nutritional and health perspectives of beans (Phaseolus vulgaris L.): an overview", Critical Reviews in Food Science and Nutrition, Vol. 54 No. 5, pp. 580-592.

Hensher, D.A., Rose, J.M. and Greene, W.H. (2005), Applied Choice Analysis: A Primer, Cambridge University Press, Cambridge.

Hole, A.R. (2007), "Estimating mixed logit models using maximum simulated likelihood", Stata Journal, Vol. 7 No. 3 , pp. $388-401$.

Hole, A.R. and Kolstad, J.R. (2012), "Mixed logit estimation of willingness to pay distributions: a comparison of models in preference and WTP space using data from a health-related choice experiment", Empirical Economics, Vol. 42 No. 2, pp. 445-469.

Horton, S. and Steckel, R.H. (2013), "Malnutrition: global economic losses attributable to malnutrition 1900-2000 and projections to 2050", in Lombard, B. (Ed.), How Much Have Global Problems Cost the Earth? A Scorecard from 1900 to, 2050, Cambridge University Press, Cambridge, pp. 247-272.

Jackson, J.C., Weatherspoon, L., Nnyepi, M., Malete, L., Mokgatlhe, L., Lyoka, P. and Bennink, M. (2013), "Sorghum bean composite porridge nutritional quality and acceptability", Nutrition \& Food Science, Vol. 43 No. 5, pp. 453-461.
Nutritionally enhanced foods

\section{$+2$}


$\mathrm{BFJ}$

121,3

KNBS (2015), Spatial Dimensions of Well-Being in Kenya: Where are the Poor? From Counties to Wards, Kenya National Bureau of Statistics, Nairobi.

Louviere, J.J. and Woodworth, G. (1983), "Design and analysis of simulated consumer choice or allocation experiments: an approach based on aggregate data", Journal of Marketing Research, Vol. 20 No. 4, pp. 350-367.

Louviere, J.J., Flynn, T.N. and Carson, R.T. (2010), "Discrete choice experiments are not conjoint analysis", Journal of Choice Modelling, Vol. 3 No. 3, pp. 57-72.

Louviere, J.J., Hensher, D.A. and Swait, J.D. (2000), Stated Choice Methods: Analysis and Applications, Cambridge University Press, Cambridge.

Low, J.W., Arimond, M., Osman, N., Cunguara, B., Zano, F. and Tschirley, D. (2007), “A food-based approach introducing orange-fleshed sweet potatoes increased vitamin a intake and serum retinol concentrations in young children in rural Mozambique", Journal of Nutrition, Vol. 137 No. 5, pp. 1320-1327.

McFadden, D. (1973), "Conditional logit analysis of qualitative choice behavior", Frontiers in Econometrics, pp. 105-142.

Mabaya, E., Jordaan, D., Malope, P., Monkhei, M. and Jackson, J. (2010), “Attribute preferences and willingness to pay for fortified cereal foods in Botswana", Agrekon, Vol. 49 No. 4, pp. 459-483.

Meemken, E.M., Veettil, P.C. and Qaim, M. (2017), "Toward improving the design of sustainability standards - a gendered analysis of farmers' preferences”, World Development, Vol. 99, pp. 99285-99298.

Meenakshi, J.V., Banerji, A., Manyong, V., Tomlins, K., Mittal, N. and Hamukwala, P. (2012), "Using a discrete choice experiment to elicit the demand for a nutritious food: willingness-to-pay for orange maize in rural Zambia”, Journal of Health Economics, Vol. 31 No. 1, pp. 62-71.

Ministry of Lands, Housing and Urban Development (2014), "Slum settlements in Kampala", Request made by John Nsubuga, August 15, available at: http://askyourgov.ug/request/slum _ settlements_in_kampala?unfold=1\#incoming-35 (accessed November 2, 2016).

Mukumbu, M. and Jayne, T.S. (1995), Urban Maize Meal Consumption Patterns: Strategies for Improving Food Access for Vulnerable Urban Households in Kenya, Productive Sector Growth and Environment Division, Office of Sustainable Development, Bureau for Africa, US Agency for International Development, Washington, DC.

Ndagire, C.T., Muyonga, J.H., Manju, R. and Nakimbugwe, D. (2015), "Optimized formulation and processing protocol for supplementary bean-based composite flour", Food Science \& Nutrition, Vol. 3 No. 6, pp. 527-538.

Nuss, E.T. and Tanumihardjo, S.A. (2010), "Maize: a paramount staple crop in the context of global nutrition", Comprehensive Reviews in Food Science and Food Safety, Vol. 9 No. 4, pp. 417-436.

Ochieng, D.O., Veettil, P.C. and Qaim, M. (2017), "Farmers' preferences for supermarket contracts in Kenya”, Food Policy, Vol. 68, pp. 100-111.

Priya, V.P., Celine, V.A., Gokulapalan, C. and Rajamony, L. (2007), "Screening amaranth genotypes ('Amaranthus' spp.) for yield and resistance to leaf blight caused by" Rhizoctonia solani 'Kuhn', Plant Genetic Resources Newsletter (Bulletin de Ressources Phytogénétiques) (Noticiario de Recursos Fitogenéticos), No. 149, pp. 1-4.

Qaim, M., Stein, A.J. and Meenakshi, J.V. (2007), "Economics of biofortification", Agricultural Economics, Vol. 37 No. S1, pp. 119-133.

Schipmann, C. and Qaim, M. (2011), "Supply chain differentiation, contract agriculture, and farmers' marketing preferences: the case of sweet pepper in Thailand", Food Policy, Vol. 36 No. 5, pp. 667-677.

Tacoli, C. (2017), "Food (in)security in rapidly urbanising, low-income contexts", International Journal of Environmental Research and Public Health, Vol. 14 No. 12, p. 1554.

Thompson, B. and Amoroso, L. (2011), Combating Micronutrient Deficiencies: Food-based Approaches, $\mathrm{FAO}$ and CABI, Rome. 
Train, K.E. (2009), Discrete Choice Methods with Simulation, Cambridge University Press, Cambridge.

UBOS (2014), "National population and housing census 2014", Sub-county Report, Volume I Central Region, Uganda Bureau of Statistics, Kampala.

UN-Habitat (2010), State of the World's Cities 2010/2011: Bridging the Urban Divide, Earthscan, London.

Vassalos, M., Hu, W., Woods, T., Schieffer, J. and Dillon, C. (2016), "Risk preferences, transaction costs, and choice of marketing contracts: evidence from a choice experiment with fresh vegetable producers", Agribusiness, Vol. 32 No. 3, pp. 379-396.

Nutritionally enhanced foods

Veettil, P.C., Speelman, S., Frija, A., Buysse, J. and Van Huylenbroeck, G. (2011), "Complementarity between water pricing, water rights and local water governance: a Bayesian analysis of choice behaviour of farmers in the Krishna river basin, India”, Ecological Economics, Vol. 70 No. 10, pp. 1756-1766.

World Bank (2017), "International comparison program database”, World Data Bank, available at: https://data.worldbank.org/indicator/PA.NUS.PRVT.PP (accessed October 20, 2017).

\section{Appendix. Instructions for the choice experiment in Nairobi}

We would now like to do a short experiment with you, where you will be presented different versions of porridge flour and asked which version you would prefer. The aim of this experiment is to help us understand ways through which the nutritional value of traditional porridge flour could be improved, taking into account consumer preferences. We have developed different versions of porridge flour with varying attributes. Note that not all of the versions of porridge flour we will show you are yet available in the market. But we would kindly ask you to choose between the versions presented just as if all of them were already available in the market.

Before presenting the different porridge flour types, I will briefly explain the different attributes. The first attribute is flour ingredients. Most of the traditional porridge flour is made from millet (maize in Kampala). In the new and nutritionally enhanced versions, we combine millet with several other ingredients, all of which contain nutrients that are important for human health. Millet and maize are largely composed of carbohydrates, which provide energy. Beans, on the other hand, are good sources of protein important for body development. Beans also contain iron and zinc, important for blood production and the body's immune system. Amaranth and orange fleshed sweet potatoes (OFSP) contain vitamin A, which is important for eyesight and the body's immune system. These ingredients are therefore combined in various ways (adjusted accordingly for Kampala):

(1) "Millet only" - means the flour is made from millet only;

(2) "Millet and maize" - means the flour is made from a combination of millet and maize;

(3) "Millet and beans" - means the flour is made from a combination of millet and beans;

(4) "Millet and OFSP" - means the flour is made from a combination of millet and OFSPs; and

(5) "Millet and amaranth leaves" - means the flour is made from a combination of millet and amaranth leaves.

The second attribute is the level of processing. Here, we have two options:

(1) straight-run flour - this is unrefined whole meal; and

(2) sifted flour - this is highly refined flour.

The third attribute is fortification. Fortification means that nutrients are added by the manufacturers during flour processing. The traditional porridge flour is not fortified. In the new versions, the flour is fortified with vitamin A, iron and zinc. These nutrients all have important functions for body health, as mentioned above. The two possible options are:

(1) "No" - the flour is not fortified with vitamin A, iron and zinc; and

(2) "Yes" - the flour is fortified with vitamin A, iron and zinc.

The fourth attribute is product price, always referring to a one kilogram package of porridge flour. Prices in the different options will range from KES 80 to KES 130 (adjusted accordingly for Kampala). 
$\mathrm{BFJ}$

121,3

Note that the price indicated is hypothetical. You do not have to pay the price now, but you should make your choice as you would when standing in a shop and choosing between different versions of porridge flour.

Now, I am going to present to you six choice cards, one after the other. Each choice card shows three versions of porridge flour (options A, B and C). The first two options (A and B) are always varying in terms of the combination of attributes, while the third option $(C)$ is always the traditional form of porridge flour commonly found in the market. From each choice card, please choose the one option that you like best.

\section{Corresponding author}

Rosina Wanyama can be contacted at: rwanyam@gwdg.de

For instructions on how to order reprints of this article, please visit our website: 